\title{
The Status and Contributing Factors for Students' Dropout in Primary Schools of Pastoralist Areas of Sewena Woreda, Bale Zone, Oromia
}

\author{
Bezabih Wondimu Kibret $(\mathrm{PhD})$ \\ Assistant Professor in Curriculum Design and Development, Department of Educational Planning and \\ Management, College of Education and Behavioral Studies, Madda Walabu University, Bale-Robe/ Ethiopia \\ Samson Abebe \\ Department of Curriculum and Teachers' Professional Development Studies, Bale Zone Education Office, Bale \\ - Robe/ Ethiopia
}

\begin{abstract}
The purpose of this study was to investigate the status and contributing factors for students' dropout in primary schools of pastoralist areas of Sewena Woreda, Bale Zone, Oromia. Pragmatism as a philosophical assumption was employed. The mixed research method more specifically concurrent triangulation design was used. Both probability and none probability sampling techniques were employed.13 primary schools were randomly selected specifically by using lottery method. $37(30 \%)$ primary school teachers, and $36(30 \%)$ dropout returnee students were selected by proportionated simple random sampling technique and Kebele Education Training Board (KETB) members two from each primary schools were purposively selected for the study. 13 primary school principals, ten CRC supervisors and six educational experts were chosen using availability sampling technique. Questionnaires were distributed for 102(teachers, principals, Cluster resource Center (CRC) Supervisors, educational experts and dropouts' returee students). Interviews were also conduct with 26 purposively selected KETB members. Questionnaires, interview, and document analysis were used as data collection tools; thereby validity and reliability were used to test the quality of instruments. Both quantitative and qualitative data analysis techniques were employed. Descriptive statistics like frequency distribution, percentage, mean and standard deviation; inferential statistics ANOVA were used. The research findings concluded that there were six major factors contributing for students' dropout in the target area. These are social factors, economic factors; school related factors; student related factors; climatic factors and political factors were identified as major and significant dropout factors. The study recommended with emphasis that the government as well as educational stakeholders should design the ways of improving the lives of pastoralists in contacting with different valuable NGOs. In addition, the Government should decide the exact and specific regional boundaries so as to solve the border conflict that brought community migration and displacement being the cause of students' dropout in both Somalia Regional State and Oromia Regional State.
\end{abstract}

Keywords: Factors, Dropout, Pastoralists, Primary School, Status,

DOI: $10.7176 / \mathrm{JEP} / 10-34-07$

Publication date: December $31^{\text {st }} 2019$

\section{Introduction \\ Background of the Study}

Dropout is a series problem at every level in which the problem starts in primary schools and continue in secondary schools which make an early intervention necessary to try to prevent students from continuing on this path through their educational experiences (Marie-JoseTheunissen-Lamers, 2016). This expresses that dropout is an alarming issue, which affects the socio economic development. Dropout does not only affect the community they belong but also affect the nation at large. Globally, the education system characterized by the high number of children leaving school before completing primary education, which results about 31.2 million primary students dropped out of school in 2010 (UNESCO, 2012).Even though, little and uneven progress has been made in reducing the rate in which children dropout before reaching the last grade of primary school; on average the dropout rate across the developing world shows 1 in 4 children who enrol in primary school withdraw before completing it(SIDA,2016;UIS and UNICEF,2015)

Moreover, despite global pledges to achieve Education for All by 2015, nearly 58 million children of primary school age worldwide were not enrolled in school in 2012, but less than one quarter of these 'out-ofschool' children were dropouts. (UIS and UNICEF, 2015: 23). In East Asia and the Pacific, 59\% of primary school aged children who were not enrolled in school in 2012 had dropped out (MICS, 2014). On the other hand, Sub-Saharan African countries characterized by high dropout rate resulting 10 million children dropout of primary school yearly. In addition, more than 2 in 5 children who begin primary school do not complete their education. Dropout vary extremely by country, especially in Ethiopia, Malawi and Uganda with dropout rates 
between $24 \%$ and $28 \%$ in the first grade, this shows dropout is huge problem in Sub-Saharan African countries; more than half of all children aged 10 to 19 had left primary school without completion (MICS, 2014; Bruneforth, 2006)

There are differences in school completion between children from urban and rural areas. Therefore, more than $80 \%$ of rural children as well as less than half of this amount of urban children had left primary school dropout in Sub-Saharan countries. There are also vast differences between poorest and richest; more than $90 \%$ of children from the poorest $40 \%$ of households who left primary school did not complete it as well as dropout is much less for the richest $40 \%$ of households. In addition, differences are also strong in relation to the mothers' education in Burkina Faso, Ethiopia, Mali and Mozambique; more than $70 \%$ of children with uneducated mothers who left primary school did not complete primary education (Hunt, 2008).

The MoE of Ethiopia, data of 2016 showed that primary school dropout rates are at $11.65 \%$ of school age students of primary. Particularly, Dropout is highest in grade 1, at $18 \%$. This means that many children join in grade 1 and then leave the education system. Dropout in the rest of the grades is around $9 \%$ (MoE, 2016). On the other hand, in evaluating Ethiopia's progress towards MDG, the gross enrolment rate in primary education increased from 96.4 percent in 2010/11 to 111.4 percent in 2016/17 (MoE, 2017). The target set by the Ethiopian Government for dropout rates of children from primary school was 9 percent for the year 2016/17(MoE,2017). The actual dropout rate in this same year is 11.65 percent, and the difference in rates between boys and girls was almost zero. To give more emphasis, in Ethiopia, household poverty is a major factor keeping many children out of school. Poor households often cannot afford to send their children to school or are forced to withdraw children out of school at early ages. Although primary school is free in Ethiopia, hidden costs such as exercise books, supplies, uniforms and food hinder poor households from sending their children to school(MoE, 2017).

Furthermore, MoE (2017) Ethiopian Education services in pastoralist areas are limited. Pastoralists derive most of their food source and income from raising livestock, a livelihood necessitating seasonal migration. Especially, in times of drought and famine, children may not be able to attend school or concentrate due to hunger, lack of water or illness induced by malnutrition. Children quit from their schooling to help collect water, fuel, or food, and the practice of early marriage (MoE, 2017. Moreover, as it was indicated in the ministry document Dropout is highest in grade 1, at 18\% nationally. This means that many children join in grade 1 and then leave the education system, whereas the dropout rate escalates to $4.49 \%$ for both sexes in Oromia as well as in Bale Zone was 2.79 in the year 2016/17. However, according to Bale Zone report, in 2016/17 academic year the primary schools rate of grade 1-4 was 2.87 whereas rate of grade 5-8 was 2.71.In addition, Bale Zone Education Office quarterly report revealed that the total primary school dropout rate of it was $2.91 \%$ or 11,287 students dropped out in the year 2016/17. Particularly, in the same year the report jotted down the total primary school dropout rate of Sewena Woreda was $7.9 \%$ or 1253 students dropped out without completing their primary education. This study is therefore imperative to reduce the status of pastoralist students' dropout in primary schools of Sewena Woreda, Bale Zone, Oromia.

\section{Statement of the Problem}

The objectives of primary education is to develop the physical, mental ,potential and the problem solving capacity of individuals by expanding education in particular by providing basic education for all (MoE, 1994). These objectives have not been fully achieved due to the high level of pastoralist students dropping out. Dropping out is a serious problem because it denies fundamental human right of individual student to education by early departure of a student from school without completion of a given grade level (MoE, 2015). Dropout has serious negative implications for the individuals who drop out, their families, and society as a whole.It should be the concern of every member of society since it has negative consequences both at individual and societal level (Koskei, Tonui, and Simiyu, 2015).

In most of the studies cited in the background, the status of students' dropout identified lack of parental involvement, peer pressure; parents do not want to send their children to schools stated as the main factors for students' dropouts. There is an urgent need for more information regarding the status of students drop out of both sexes. An explanation of why both sexes of pastoral students drop out of primary school is needed in order to address this problem. The influences on students drop out for females have been explored by few Ethiopian studies. In the target area a Cross-sectional studies by (Teshome Sirak \&Gamachu Gishe,2016) have verified specific dropout factors namely; students walk the long distance to school, and children always move from place to place with their family while their families migrate from one place to the other due to the mobile nature of pastoralists.

However, dropout does not occur through a single factor; it is a composition of several factors. A number of studies have been conducted on girls' dropout issue based on particular regions, societies and cultural perspectives in various parts of the world. Thus, this study tends to investigate the untouched parts by the previous study like the status of dropout which are organized in accumulated factors and can give further 
opportunity to researchers to view the status of students' dropout issue. Mainly, this study set out to investigate the status and contributing factors for students' dropout in primary schools of pastoralist areas of Sewena Woreda, Bale Zone, Oromia. To fill the gaps of the study, the following basic research questions were raised and answered in the course of the study.

1. What is the status of students' dropout in primary schools of pastoralist areas of Sewena Woreda, Bale Zone, Oromia?

2. What are the factors contributing for students drop out in primary schools of pastoralist areas of Sewena Woreda, Bale Zone, Oromia?

3. What are impacts observed as results of students' dropout in primary schools of pastoralist areas of Sewena Woreda, Bale Zone, Oromia?

\section{Theoretical Framework of the Study}

A combination or hybrid of a social learning theory and facilitating learning theories were chosen as a theoretical framework for this study. First, the study employed predominantly social learning theory as a theoretical framework for this study. This theory was based on the idea that we learn from our interactions with others in a social context (Nabavi,2014). Separately, by observing the behaviors of others, people develop similar behaviors. According to Bandura (1977), imitation involves the actual reproduction of observed motor activities. Moreover, in social learning theory there were different social units with whom children connects; family, school, peers and community. In conducting education children have interaction of different people having different habit and characters. Therefore, children can imitate or cope with the behavior of others.

Furthermore, social learning theory emphasize on changes in behavior and learning through the observation and imitation of the actions and behaviors in the environment. It models the child's behavior to reflect the acceptable norms, attitudes and values in the society (Edinyang, et al, 2015). Therefore, this theory was important that they all verify that a social phenomenon like school dropout was a developmental concern influenced by various factors and context which happens over a period of time and not just as a single event. In considering all the above point, the social learning theory added additional substance to the theoretical basis within which I would interpret the findings of this study of the status of school dropout in Sewena Woreda Bale Zone, Oromia.

Secondly, the facilitation theory of learning was based on the belief that man was a unique creature with varying capacities, and a natural desire to learn. Educators recognize and achieve this natural desire of acquiring knowledge. Learning therefore should aim at achieving this desire thus bringing about self-actualization (Bouchard, T., 2013). In this context, learners should be helped to gain control over their own education and take responsibility of their own learning. Therefore, this allows the researcher to interpret learners' roles, interpretation and understanding of the learner dropout phenomenon. It provided a clear perspective for this study because it explored the participants' feelings, actions, intentions, experiences and their views with regard to the causes of dropout in primary schools of Sewena Woreda, Bale Zone, Oromia.
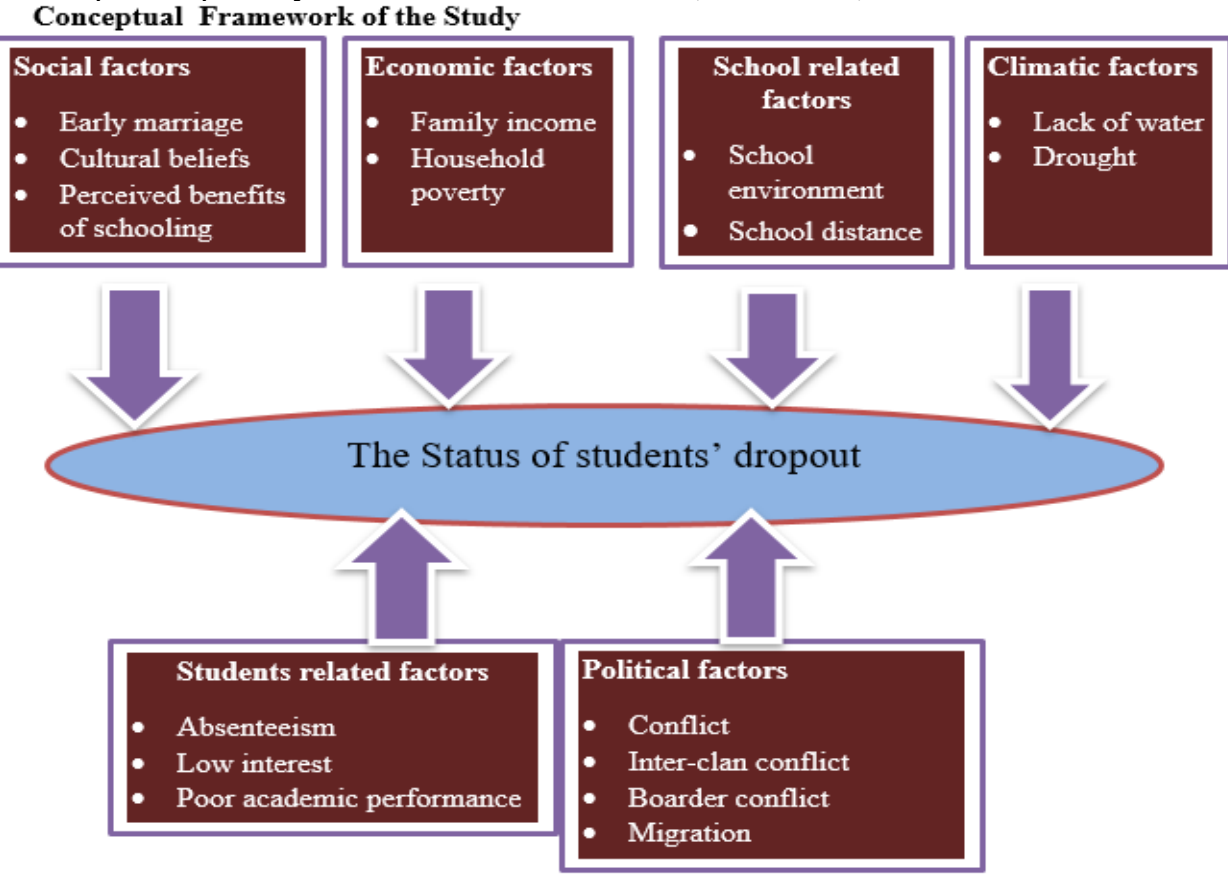

Figure 1.Conceptual framework on students' dropout 
The conceptual framework clearly indicates the status of students' dropout in primary schools of Sewena Woreda, Bale Zone, Oromia by achieving the goals of schools were used by solving the school related factors; students related factors, economic factors; social factors, climatic factors and political factors. All the above factors considered as to be the dependent variables that contribute individually or collectively to the status of students' dropout in primaryschools and also considered as independent variables used in this study.

\section{Research Method and Design of the Study \\ Paradigm}

As mentioned in the outset of the study, the purpose of this research article was to investigate status and contributing factors students' dropout in primary schools as an assumption and know about how and what was investigated during this research problem. This is because pragmatism paradigm mixes characteristics of quantitative and qualitative approaches and identifies solutions (Morgan, 2007). Moreover, the pragmatism paradigm provided the opportunities to the researchers to choose multiple research methods and techniques. Therefore, authors were used mixed research method more specifically concurrent triangulation mixed research design to investigate the status of students dropout in primary schools of pastoralist areas of Sewena Woreda, Bale Zone, Oromia based on testing the basic research questions.

\section{Population of the Study}

Population has defined as any group of people in which the researchers happens to be interested. Omari, (2011) says that Population is the totality of any group of units which have one or more characteristics in common that are of interest. Thus, target population for this study was 124 primary school teachers, 120 dropout returnee students, 13 primary school directors, 10 CRC supervisors, 18 educational experts and 104 KETB members. Therefore, the total population for this study was 389 .

\section{Types and Sources of Data}

Both primary and secondary sources of data were used. Specifically, the major sources of primary data becomes primary school teachers, (CRC) supervisors, directors, dropout returnee students, educational experts and Kebeles education and training board (KETBs) of government primary schools of Sewena Woreda, Bale Zone,Oromia Region. The secondary sources of data were document analysis from Sewena Woreda Education Office.

\section{Sample Size and Sampling Techniques}

In this study, the sample schools were chosen from 42 primary schools, $13(30 \%)$ schools were chosen by using simple random sampling method specifically by using lottery method. Since Mugenda and Mugenda (1999) advises researchers to use $10-30 \%$ of samples from primary schools to gravitate the representative of the population. On the other hand, $13(30 \%)$ of primary schools directors, $10(100 \%)$ of CRC supervisors and $6(30 \%)$ of educational experts were chosen using availability sampling technique. In addition, 37(30\%) primary teachers, $36(30 \%)$ dropout returnee students were selected proportionated simple random sampling technique, and 26 KETB members two (chairman and secretary) from sample schools were selected by purposive sampling technique.

\section{Data Collection Instrument}

Questionnaire, interview, and document analysis were used as a main data gathering instruments.

\section{Validity}

Mugenda and Mugenda (1999) define validity as the accuracy and meaningfulness of inferences which are based on the research results. To this end, experts were consulted to check if instruments were well designed in relation to the research objectives. To ensure validity and reliability of data, the authors are used triangulation methods in data collection strategy for improving the validity and reliability of research findings as commented by Creswell (2012) which states that described that triangulation means the use of different data sources of information by examining evidence from these sources and using them to build a coherent justification for theme.

\section{Reliability}

Reliability is an essential ingredient in validity because a test cannot be valid if it is not reliable (Borg and Gall, 1993). Therefore, the instruments were pilot tested at a primary school. Questionnaires were piloted on twenty respondents who were not taking part in the sample. To check reliability using cronbach's alpha and obtained 0.86 alpha coefficients which was considered as reliable for data collection. Therefore, the result of the test showed that the reliability of cronbach's alpha \& alpha should falls at acceptable range (i.e. $\alpha \geq 0.75$ ). 


\section{Methods of Data Analysis}

Both quantitative and qualitative data analysis techniques were used. Quantitative data were analyzed by means of descriptive and inferential statistics (frequency distribution, percentage, mean, standard deviation) and ANOVA. Whereas, direct quotation and paraphrasing were used to analyze qualitative data collected through interviews and document analysis.

\section{Data Presentation, Analysis and Interpretation}

This part focused on the outcome of data analysis. It was presented along each basic research questions. The findings were presented in relation to the following themes: the status of students' dropout in primary schools; the factors contributing for students' dropout of primary schools and indicating the impacts or consequences of students' dropout in primary schools. It is, thus, presented the data gathered through questionnaire, interview and eighth years (2011-2018) document analysis of Sewena Education Office statistical report have checked on students' enrollment and dropout status.

1.1. Status of students' dropout rates by sex in percent and year 2011-2018

Table 1.Stauts of students' dropout rates by sex in percent and year 2011-2018

\begin{tabular}{cccccccc}
\hline \multirow{2}{*}{$\begin{array}{c}\text { Academic } \\
\text { Years }\end{array}$} & \multicolumn{7}{c}{ Primary Students dropout rates in 2011-2018 } \\
\cline { 2 - 8 } & M & $\%$ & F & $\%$ & M+F & $\%$ & Ranks \\
\hline $\mathbf{2 0 1 1}$ & 81 & 6.8 & 54 & 5.6 & 135 & 6.27 & 3 \\
$\mathbf{2 0 1 2}$ & 144 & 7.97 & 79 & 4.72 & 223 & 6.41 & 2 \\
$\mathbf{2 0 1 3}$ & 120 & 7.43 & 74 & 4.48 & 194 & 5.94 & 4 \\
$\mathbf{2 0 1 4}$ & 72 & 6.34 & 35 & 3.80 & 107 & 5.21 & 5 \\
$\mathbf{2 0 1 5}$ & 107 & 5.19 & 67 & 4.21 & 174 & 4.76 & 7 \\
$\mathbf{2 0 1 6}$ & 134 & 5.02 & 85 & 4.59 & 219 & 4.85 & 6 \\
$\mathbf{2 0 1 7}$ & 132 & 8.6 & 82 & 7.4 & 214 & 8.09 & 1 \\
$\mathbf{2 0 1 8}$ & 110 & 3.11 & 73 & 3.26 & 183 & 3.16 & 8 \\
\hline $\mathbf{2 0 1 1 - 2 0 1 8}$ & $\mathbf{8 8 9}$ & $\mathbf{5 . 7 1}$ & $\mathbf{5 6 0}$ & $\mathbf{4 . 6 6}$ & $\mathbf{1 4 4 9}$ & $\mathbf{5 . 2 5}$ & \\
\hline
\end{tabular}

The table showed that dropout rate of primary students indicated from highest to lowest in the years of $2017,2012,2011,2013,2014,2016,2015$ and 2018 respectively. that is, male $132(8.6 \%)$, female $82(7.4 \%)$ total 214(8.09\%); male144 (7.97\%), female79 (4.72\%) and total 223(6.41\%); male 81(6.8\%),female 54(5.6\%) and total 135(6.27\%);male 120(7.43\%),female 74(4.48\%) and total 194(5.94\%); male 72(6.34\%), female 35(3.80\%) and total 107(5.21\%); male 134(5.02\%), female 85(4.59\%) and total 219(4.85\%);male 107(5.19\%), female $67(4.21 \%)$ and total $174(4.76 \%)$ Whereas, in the year of 2018 the dropout rate was male $110(3.11 \%)$, female $73(3.26 \%)$ and total $183(3.16 \%)$ and it's the lowest of all. To conclude that, more males were dropped out than females and was highest 2017 due to highest drought, boarder conflict and migration of pastoralists in the target area during this period.

1.2. Status of students' dropout rates by grade levels in percent and year 2011-2018

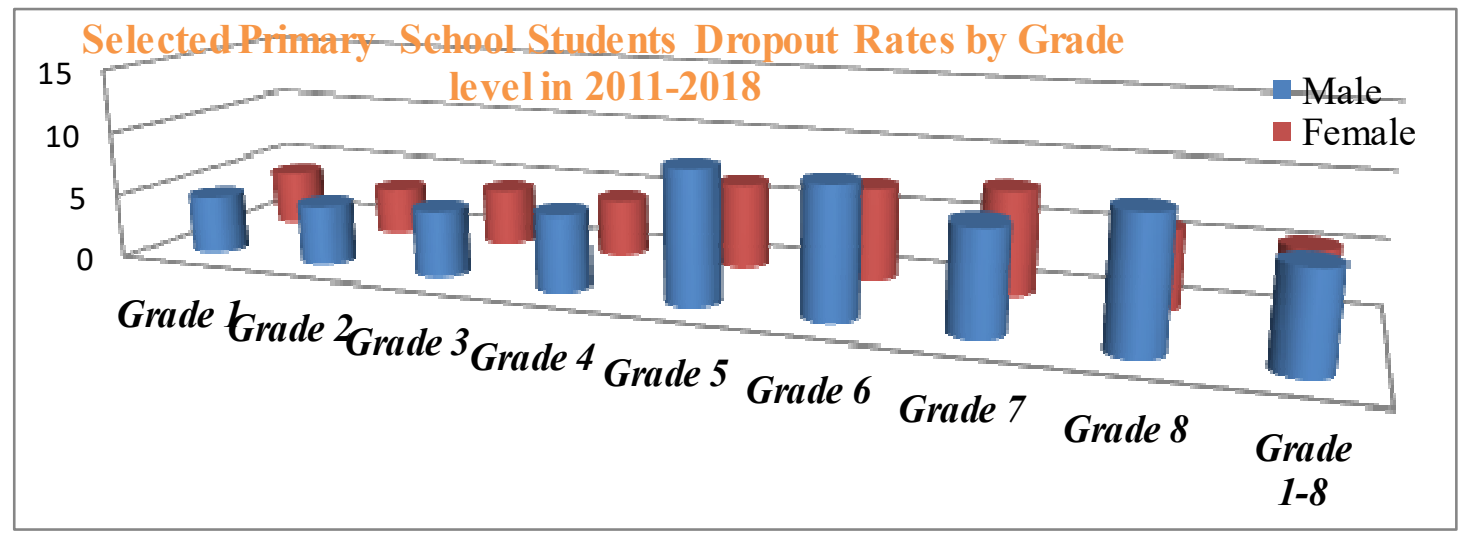

Figure 2. Status of school dropout rates by grade level and sex in percent in the year 2011 - 2018

Figure 2 showed that dropout rates were presented in all grade level and in eight academic years (20112018). More specifically, the maximum male students dropout rates had seen in grade 5,6, and 8 with rate of $120(10.2 \%), 76(9.9 \%)$ and $32(9.8 \%)$ respectively ; as well as, the maximum female students dropout rates had seen in grade 7,6 and 5 with rate of $28(7.9 \%), 47(7.2 \%)$ and $66(6.6 \%)$ respectively. The dropout rate also was high in grade 5, 6,7 and 8 for boys and in grade 5, 6, and 7for girls. Totally, within the eight years' time grade 5 up to 8 grades level the dropout rates could be increased. However, to conclude that in all grade levels within eight academic years there was dropout of students in selected primary schools, that is, grade 1 the dropout rate was male $214(4.5 \%)$ and female $148(4.3 \%)$ around 362 students dropped out from 13 primary schools. To support this idea, the qualitative data suggested that due to different dropout factors the above mentioned data of 
students dropped out from their schooling.Findings suggest that students quit their schooling increase as the grade level also increase.

\subsection{Status of Students' Dropout by Age}

The first objective was set to explore the status of students' dropout in primary schools. To achieve this aspect, let's see the following table.

Table 2. The status of students' dropout by age

\begin{tabular}{|c|c|c|c|c|c|c|c|c|c|c|c|c|c|}
\hline \multirow[t]{2}{*}{ № } & \multirow[t]{2}{*}{ Items } & \multicolumn{2}{|c|}{$\begin{array}{r}\text { Teachers } \\
\mathbf{N}=37\end{array}$} & \multicolumn{2}{|c|}{$\begin{array}{c}\text { Principals } \\
\quad \mathrm{N}=13\end{array}$} & \multicolumn{2}{|c|}{$\begin{array}{l}\text { Supervisor } \\
\qquad \mathbf{N}=\mathbf{1 0}\end{array}$} & \multicolumn{2}{|c|}{$\begin{array}{c}\text { Edu.experts } \\
\qquad \mathbf{N}=6\end{array}$} & \multicolumn{2}{|c|}{$\begin{array}{l}\text { Dropout } \\
\text { returnee } \\
\qquad \mathbf{N}=36\end{array}$} & \multicolumn{2}{|c|}{$\begin{array}{l}\text { Total } \\
N=102\end{array}$} \\
\hline & & $\mathrm{f}$ & $\%$ & $\mathrm{f}$ & $\%$ & $\mathrm{f}$ & $\%$ & $\mathrm{f}$ & $\%$ & $\mathrm{f}$ & $\%$ & $\mathrm{f}$ & $\%$ \\
\hline \multirow[t]{5}{*}{1} & Studen & hicl & ge level & rop & ts fron & eir $s$ & ooling & & & & & & \\
\hline & $7-10$ & 4 & 10.81 & 2 & 15.4 & 2 & 20 & - & - & 5 & 13.9 & 13 & 12.74 \\
\hline & $11-14$ & 31 & 83.78 & 9 & 69.2 & 7 & 70 & 5 & 83.3 & 27 & 75 & 79 & 77.45 \\
\hline & $15-18$ & 2 & 5.4 & 2 & 15.4 & 1 & 10 & 1 & 16.7 & 4 & 11.1 & 10 & 9.8 \\
\hline & Total & 37 & 100 & 13 & 100 & 10 & 100 & 6 & 100 & 36 & 100 & 102 & 100 \\
\hline
\end{tabular}

Source: (Own Field data, 2019): $\mathrm{N}=102 \mathrm{df}=101$

Table 2 showed the frequencies of all respondents' views about the status of students' dropout in primary Schools. According to the respondents which showed 11-14 age level of students dropped out from their schooling. Furthermore, from the total respondents that could replied based on the question 'Students at which age level dropouts from their schooling' were indicated as follows: $79(77.45 \%), 13(12.74 \%)$ and 10(9.8\%) between the age of 11-14, 7-10 and 15-18 students dropped out from their schooling respectively. This implies that majority of the respondents were replied the age range11-14 of students were dropped out from their schooling.

\section{Factors Contributing for Students' Dropout}

Table 3. Social Factors Contributing for Students' Dropout

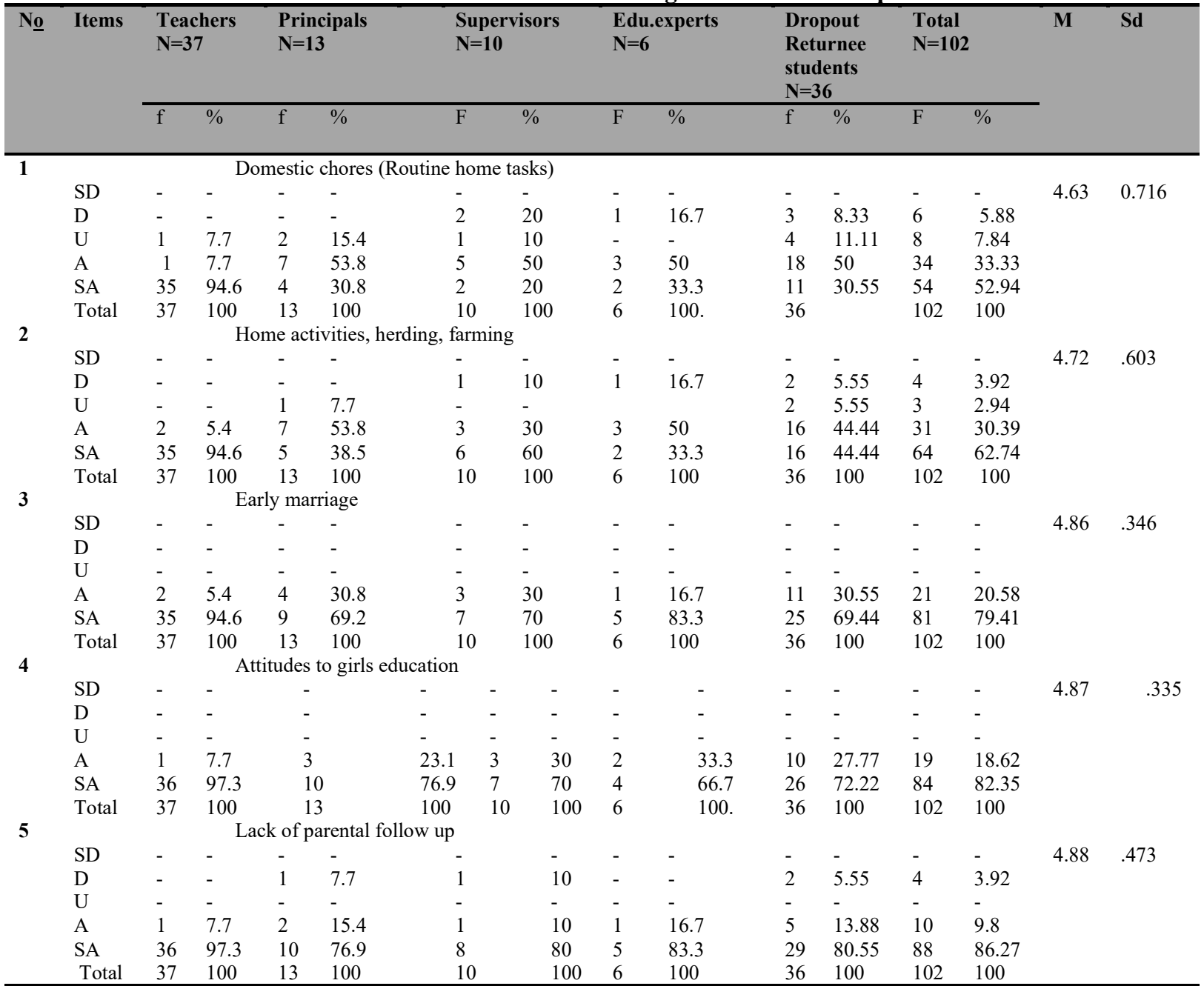




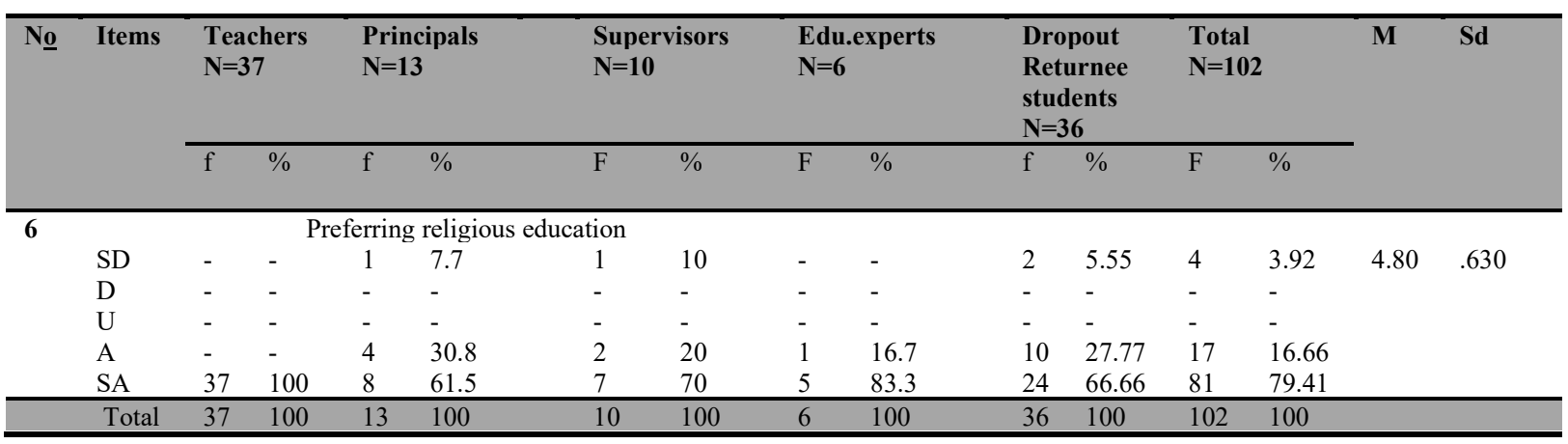

Source:(Own Field data,2019);(SD-Strongly Disagree,D-Disagree,A-Agree,SA-StronglyAgree)

As can be shown in item 1 Table 3, 88(86.27\%) of respondents replied strongly agree $54(52.94 \%)$ and agree $34(33.33 \%) ; 6(5.88 \%)$ of respondents replied disagree; whereas, $8(7.84 \%)$ of the respondents replied undecided for the statement that states domestic chores (routine home tasks)are the social factor influencing students dropout in Sewena Woreda, Bale zone, Oromia. From the analysis, the total disagreed scores for this item stating, domestic chores (routine home tasks), scored $88(86.27 \%$ ) against scores of $6(5.88 \%$ ) for disagreed. The arithmetic mean score of this item is $4.2 \mathrm{SD}$ of 1.072 which is greater than the average mean value, 3 . This show that domestic chores (routine home tasks) mainly taken as causes of students drop out in the study area. The ANOVA result for this item was $(\mathrm{F}, 14.015$ at $\mathrm{p}<0.001)$. Therefore, it shows domestic chores was highly significant that influencing students dropout.

Some interviewees have spoken the following reasons for students dropout based on domestic chores (routine home tasks)

Parents sometimes obliged their children to do domestic chores staying at home. Children work instead of their family. Due to these reasons our children dropped out from their schooling (KETBs participant)

To support the above ideas, Hunt,(2008) many children from poor households have no choice but to juggle work and school or to help with domestic chores and childcare to free up their parents to work. In some cases, family commitments clash with school schedules and lead to high absenteeism, poor school performance and (usually) dropout

As can be shown in item 2 Table 3, 95(93.13\%) of respondents replied strongly agree 64(62.74\%) and agree $31(30.39 \%) ; 4(3.92 \%)$ of respondents replied disagree; whereas, $3(2.94 \%)$ of the respondents replied undecided for the statement that states Home activities, herding, farming are the social factor influencing students dropout in Sewena Woreda, Bale zone, Oromia. From the analysis, the total agreed scores for this item stating, Home activities, herding, farming, scored 95(93.13\%) against scores of 4(3.92\%) for disagreed. The arithmetic mean score of score of this item is $4.28 \mathrm{SD}$ of .877 which is greater than the average mean value, 3 . This show that Home activities, herding, and farming mainly taken as causes of students' dropout in the study area. The ANOVA result for this item was $(\mathrm{F}, 7.513$ at $\mathrm{p}<0.001)$. Therefore, it shows Home activities, herding, and farming was highly significant that influencing students dropout.

Some interviewees have spoken the following reasons for students dropout based on domestic chores (routine home tasks):

Most of pastoralists including me ordered our children on the daily work of herding cattle;

farming and sometimes we ordered them on following farms having grains. Due to these

reasons our children dropped out from their schooling (KETBs participant)

To support the above ideas, World Bank (2017) stated that children withdraw from school to help by herding, farming, collect water, fuel and other home activities. Therefore, Home activities, herding, and farmingmainly taken as causes of students' dropout in the study area.

As can be shown in item 3 Table 3, 102(100\%) of respondents replied strongly agree $81(79.41 \%)$ and agree $21(20.58 \%)$ for the statement that states early marriage are the social factor influencing students dropout in Sewena Woreda, Bale zone, Oromia. From the analysis, the total agreed scores for this item stating, early marriage scored $102(100 \%)$ for the statement that states early marriage are the social factor influencing students dropout. The arithmetic mean score of score of this item is $4.40 \mathrm{SD}$ of .924which is greater than the average mean value, 3 . This shows that early marriage mainly taken as causes of students' dropout in the study area. The ANOVA result for this item was (F, 2.019at $\mathrm{p}<0.001)$. Therefore, it shows early marriage was highly significant that influencing students dropout.

In our culture we obliged our girls to marry after they reached puberty stage. We do not think more about their education. We like our daughters getting marriage and have got their own children rather they complete their education (KETBs committee participants)

The effect of early marriage in the study area girls dropout rate become higher because parents consider girls schooling as of no benefits when they leave their own family after getting married. Girls with lower 
socioeconomic backgrounds dropped out from school due to facing difficulties in getting marriage (Shahidul, 2012). Moreover, parents do not want their daughters to go to school, fearing that education will alienate them from traditional value and compromise their ability to be good wives and mothers (Shayan, 2015:281)

As can be shown in item 4 Table 3, 102(100\%) of respondents replied strongly agree $84(82.35 \%)$ and agree $18(17.64 \%)$ for the statement that states attitudes to girls education are the social factor influencing students dropout in Sewena Woreda, Bale zone, Oromia. From the analysis, the total disagreed scores for this item stating, attitudes to girls education scored $102(100 \%)$ for the statement that states attitudes to girls education are the social factor influencing students dropout. The arithmetic mean score of score of this item is 4.53 SD of .681which is greater than the average mean value, 3 . This shows that attitudes to girls education mainly taken as causes of students' dropout in the study area. The ANOVA result for this item was (F, 2.535at $\mathrm{p}<0.001)$. Therefore, it shows attitudes to girls education was highly significant that influencing students dropout. The above finding revealed that parents attitude to girls' education made girls dropped out from their schooling. This is supported by E, Dood (2010), as parental attitude and support had great deal of influence on girls' participation and the level of success attained in education.

In the interview KETBs committee expressed their idea according to the following theme:

Most of girls get influenced by families' low attitude to girls education because they couldn't believe on girls education. Even if girls will start their schooling families obliged them getting marriage. Then are forced to dropped out (KETBs committee Participants)

As can be shown in item 5 Table 3, 98(96.07\%) of respondents replied strongly agree $88(86.27 \%)$ and agree $10(9.8 \%) ; 4(3.92 \%)$ of respondents replied disagreed for the statement that states lack of parental follow up are the social factor influencing students dropout in Sewena Woreda, Bale zone, Oromia. From the analysis, the total agreed scores for this item stating, lack of parental follow up scored 98(96.07\%) against scores of 4(3.92\%) for the statement that states lack of parental follow up are the social factor influencing students dropout. The arithmetic mean score of score of this item is $4.40 \mathrm{SD}$ of .756 which is greater than the average mean value, 3 . This shows that lack of parental follow up mainly taken as causes of students' dropout in the study area. The ANOVA result for this item was $(\mathrm{F}, 2.793$ at $\mathrm{p}<0.001)$. Therefore, it shows lack of parental follow up was highly significant that influencing students dropout.

In the interview KETBs committee expressed their idea according to the following theme:

The mostly known reasons for students' dropout were children low interest towards their education and need parental follow up. Unless they are followed by their parents they stayed elsewhere being absent from school, finally they dropped out (KETBs committee participants)

As can be shown in item 6 Table 3, 98(96.07\%) of respondents replied strongly agree $81(79.41 \%)$ and agree $17(16.66 \%) ; 4(3.92 \%)$ of respondents replied disagreed for the statement that states preferring religious education are the social factor influencing students dropout in Sewena Woreda, Bale zone, Oromia. From the analysis, the total agreed scores for this item stating preferring religious education scored $98(96.07 \%)$ against scores of $4(3.92 \%)$ for disagreed. The arithmetic mean score of score of this item is $4.21 \mathrm{SD}$ of 1.03 which is greater than the average mean value, 3 . This shows that preferring religious education mainly taken as causes of students' dropout in the study area. The ANOVA result of all social dropout factors stated here under. Therefore, it shows preferring religious education was highly significant that influencing students dropout.

Some interviewees have spoken that pastoralist students dropped out due to preferring religious education. They said;

Our pastoralist society gives emphasis for religious education and wants their children to go to know their religion deeply. For this reason, our children also preferred religious education and go to other areas to learn Quran by quitting their schooling (KETBs committee participants)

Table 4.Summary Table for ANOVA for Social factors of students' dropout

\begin{tabular}{lllll}
\hline Source & Sum of Squares & Df & Mean Square & F \\
\hline Between Groups(Combined) & 46.471 & 4 & 11.616 & 39.136 \\
Within Groups & 171.09 & 97 & 1.764 & \\
\hline Total & 217.558 & 101 & & \\
\hline
\end{tabular}

With $\alpha=0.05$, Fcrit $=1.25$. 
3. Impacts behind the Status of Students' Dropout

Table 5. Impacts behind the status of students' dropout responded by Teachers, Principals, Supervisors,

Educational experts and dropout returnee Students

\begin{tabular}{|c|c|c|c|c|c|c|c|c|c|c|c|c|c|c|c|}
\hline \multirow[t]{2}{*}{ No } & \multirow[t]{2}{*}{ Items } & \multicolumn{2}{|c|}{$\begin{array}{l}\text { Teachers } \\
\mathbf{N}=37\end{array}$} & \multicolumn{2}{|c|}{$\begin{array}{l}\text { Principals } \\
N=13\end{array}$} & \multicolumn{2}{|c|}{$\begin{array}{l}\text { Supervisors } \\
\mathrm{N}=10\end{array}$} & \multicolumn{2}{|c|}{$\begin{array}{l}\text { Edu.expert } \\
N=6\end{array}$} & \multicolumn{4}{|c|}{$\begin{array}{l}\text { Dropout returnee } \\
\text { students } \mathrm{N}=\mathbf{3 6} \\
\text { Total } \mathrm{N}=102\end{array}$} & \multirow[t]{2}{*}{$\mathbf{M}$} & \multirow[t]{2}{*}{ Sd } \\
\hline & & $\mathrm{f}$ & $\%$ & f & $\%$ & $\mathrm{f}$ & $\%$ & $\mathrm{f}$ & $\%$ & f & $\%$ & $\mathrm{f}$ & $\%$ & & \\
\hline \multirow[t]{7}{*}{1} & \multicolumn{15}{|c|}{ Bring educational wastage in the country } \\
\hline & SD & - & - & 1 & 7.7 & 2 & 20 & 1 & 16.7 & 4 & 11.11 & 8 & 7.84 & 4.69 & .965 \\
\hline & $\mathrm{D}$ & - & - & 1 & 7.7 & 3 & 30 & - & - & 4 & 11.11 & 8 & 7.84 & & \\
\hline & $\mathrm{U}$ & - & - & - & - & - & - & - & - & - & - & - & & & \\
\hline & A & - & - & 1 & 7.7 & - & - & - & - & 2 & 5.55 & 3 & 2.94 & & \\
\hline & SA & 37 & 100 & 10 & 76.9 & 5 & 50 & 5 & 83.3 & 26 & 72.22 & 83 & 81.37 & & \\
\hline & Total & 37 & 100 & 13 & 100 & 10 & 100 & 6 & 100 & 36 & 100 & 102 & 100 & & \\
\hline
\end{tabular}

2 Being burden or load on the country in general on the family in the particular

$\begin{array}{lllllllllllllll}\mathrm{SD} & - & - & 2 & 15.4 & 3 & 30 & - & - & 5 & 13.88 & 10 & 9.8 & 4.71 & .918 \\ \mathrm{D} & - & - & - & - & - & - & - & - & - & - & - & - & & \\ \mathrm{U} & - & - & 1 & 7.7 & - & - & 1 & 16.7 & 2 & 5.55 & 4 & 3.92 & \\ \mathrm{~A} & 1 & 2.7 & 2 & 15.4 & - & - & 1 & 16.7 & 4 & 11.11 & 8 & 7.84 & \\ \mathrm{SA} & 36 & 97.3 & 8 & 61.5 & 7 & 70 & 4 & 66.7 & 25 & 69.44 & 80 & 78.43 & \\ \text { Total } & 37 & 100 & 13 & 100 & 10 & 100 & 6 & 100 & 36 & 100 & 102 & 100 & \end{array}$

3 Being participated in different criminal activities

$\begin{array}{lllllllllllll}\mathrm{SD} & - & - & - & - & - & - & - & - & - & - & - & - \\ \mathrm{D} & - & - & - & - & - & - & - & - & - & - & - & - \\ \mathrm{U} & - & - & 1 & 7.7 & 1 & 10 & - & - & 2 & 5.55 & 4 & 3.92 \\ \mathrm{~A} & 2 & 5.4 & 2 & 15.4 & 1 & 10 & - & - & 5 & 13.88 & 10 & 9.8 \\ \mathrm{SA} & 35 & 94.6 & 10 & 76.9 & 8 & 80 & 6 & 100 & 29 & 80.55 & 88 & 86.27 \\ \text { Total } & 37 & 100 & 13 & 100 & 10 & 100 & 6 & 100 & 36 & 100 & 102 & 100\end{array}$

4 The number of illiteracy will be increased

$\begin{array}{lllllllllllll}\text { SD } & - & - & - & - & - & - & - & - & - & - & - & - \\ \text { D } & - & - & 1 & 7.7 & 1 & 10 & - & - & - & - & 2 & 1.96 \\ \text { U } & - & - & 1 & 7.7 & & & - & - & 4 & 11.11 & 5 & 4.90 \\ \text { A } & 1 & 2.7 & 3 & 23.1 & 2 & 20 & 1 & 16.7 & 8 & 22.22 & 15 & 14.7 \\ \text { SA } & 36 & 97.3 & 8 & 61.5 & 7 & 70 & 5 & 83.3 & 24 & 66.66 & 80 & 78.43 \\ \text { Total } & 37 & 100 & 13 & 100 & 10 & 100 & 6 & 100 & 36 & 100 & 102 & 100\end{array}$

5 Reduce productivity income

\begin{tabular}{|c|c|c|c|c|c|c|c|c|c|c|c|c|c|}
\hline SD & - & - & - & - & - & - & - & - & - & - & - & - & $4.88 \quad .324$ \\
\hline $\mathrm{D}$ & - & - & - & - & - & - & - & - & 2 & 5.55 & 2 & 1.96 & \\
\hline $\mathrm{U}$ & - & - & - & - & - & - & - & - & 2 & 5.55 & 2 & 1.96 & \\
\hline A & 1 & 2.7 & 3 & 23.1 & 2 & 20 & - & - & 8 & 22.22 & 14 & 13.72 & \\
\hline SA & 36 & 97.3 & 10 & 76.9 & 8 & 80 & 6 & 100 & 24 & 66.66 & 84 & 82.35 & \\
\hline Total & 37 & 100 & 13 & 100 & 10 & 100 & 6 & 100 & 36 & 100 & 102 & 100 & \\
\hline
\end{tabular}

Source: (Own Field data, 2019) ; SD-Strongly Disagree, D-Disagree, A-Agree, SA-Strongly Agree): $\mathrm{N}=102 \mathrm{df}=101$

As can be indicated in item 1 Table 5 showed, 83(81.37\%) of the respondents replied strongly agreed and $3(2.94 \%)$ of the respondents replied agreed for the statement bring educational wastage in the country could be the impact behind the status of students' dropout. Whereas, $8(7.84 \%)$ of the respondents replied disagreed and $8(7.84 \%)$ of the respondents replied strongly disagreed with the statement bring educational wastage in the country could be the impact behind the status of students' dropout. The score for the total agreed for the item stood at $86(84.31 \%)$ for the statement bring educational wastage in the country could be the impact behind the status of students' dropout. The arithmetic mean score of this item is 4.83 at the standard deviation of 0.424 which is greater than the average mean score 3, showing bring educational wastage in the country could be the impact behind the status of students' dropout in Sewena Woreda, Bale Zone, Oromia.The ANOVA result for this item was $(\mathrm{F}, 9.627$ at $\mathrm{p}<0.001)$. Therefore, bring educational wastage in the country could be highly significant impact behind the status of students' dropout.

To help the above idea in interview some respondents described as;

Dropout by itself is educational wastage. For instance, dropout students may forget the 
knowledge gained before, they may be misbehaved in the society. On the other hand, those students whom dropped out from their schooling become burden (load) on their families as well as on the government (KETBs committee participants)

Teachers and other professional educators have a solemn duty to ensure that money spent on education actually enables students to a cquire the necessary knowledge and skill of the subjects and lessons of each grade before they move on to the next higher grade or level. A high rate in the number of dropouts and repeaters indicates the inefficiency (wastage) of the educational system itself (APHA, 2018).Therefore, dropout of students bring educational wastage in the country could be the impact behind the status of students dropout.

As can be indicated in item 2 Table 5 showed, 80(78.43\%) of the respondents replied strongly agreed and $8(7.84 \%)$ of the respondents replied agreed for the statement Being burden or load on the country in general on the family in the particular could be the impact behind the status of students' dropout. Whereas, $10(9.8 \%)$ of the respondents replied strongly disagreed with the statement being burden or load on the country in general on the family in the particular could be the impact behind the status of students' dropout. About 4(3.92\%)of the respondents replied undecided with the statement being burden or load on the country in general on the family in the particular could be the impact behind the status of students' dropout. The score for the total agreed for the item stood at $88(86.27 \%$ ) against the score of $2(1.96 \%)$ for the statement being burden or load on the country in general on the family in the particular could be the impact behind the status of students' dropout. The arithmetic mean score of this item is 4.83 at the standard deviation of 0.424 which is greater than the average mean score 3 , showing being burden or load on the country in general on the family in the particular could be the impact behind the status of students' dropout in Sewena Woreda, Bale Zone, Oromia.The ANOVA result for this item was $(\mathrm{F}, 6.632$ at $\mathrm{p}<0.001)$. Therefore being burden or load on the country in general on the family in the particular could be highly significant impact behind the status of students' dropout.

To help the above idea in interview some respondents described as;

Since most of Pastoralists have chronic poverty. Beside this their children dropped out due to different cases as well as they become burden on their family and bothered them (KETBS committee participants)

As can be indicated in item 3 Table 5 showed, 88(86.27\%) of the respondents replied strongly agreed and $10(9.8 \%)$ of the respondents replied agreed for the statement being participated in different criminal activities could be the impact behind the status of students' dropout. About 4(3.92\%) of the respondents replied undecided with the statement being participated in different criminal activities could be the impact behind the status of students' dropout. The score for the total agreed for the item stood at 98(96.07\%)for the statement being participated in different criminal activities could be the impact behind the status of students' dropout. The arithmetic mean score of this item is 4.83 at the standard deviation of 0.424 which is greater than the average mean score 3, showing being participated in different criminal activities could be the impact behind the status of students' dropout in Sewena Woreda, Bale Zone, Oromia. The ANOVA result for this item was (F, 1.739at $\mathrm{p}<0.001)$. Therefore, being participated in different criminal activities could be highly significant impact behind the status of students' dropout.

To help the above idea in interview some respondents described as;

Dropout students may participate in violence unemployment man power will be increased in the country. Totally the educational wastage may lead to economic, social and political crisis of the society in particular in the country as a whole (KETBs committee participants)

The above idea is supported with the following individual idea. The impacts behind students dropout makes students to participate in different criminal activities and People feel that because of the unfavorable environment in government or public schools, many students feel disengaged in school often interrelated to eventual dropouts (Attaullah, 2000).

As can be indicated in item 4 Table 5 showed, 80(78.43\%) of the respondents replied strongly agreed and $15(14.7 \%)$ of the respondents replied agreed for the statement the number of illiteracy will be increased could be the impact behind the status of students' dropout. Whereas, 2(1.96\%) of the respondents replied strongly disagreed with the statement the number of illiteracy will be increased could be the impact behind the status of students' dropout. About5(4.90\%) of the respondents replied undecided with the statement the number of illiteracy will be increased could be the impact behind the status of students' dropout. The score for the total agreed for the item stood at 99(97.05\%) for the statement the number of illiteracy will be increased could be the impact behind the status of students' dropout. The arithmetic mean score of this item is 4.83 at the standard deviation of 0.424 which is greater than the average mean score 3 , showing the number of illiteracy will be increased could be the impact behind the status of students' dropout in Sewena Woreda, Bale Zone, Oromia.The ANOVA result for this item was $(\mathrm{F}, 3.224$ at $\mathrm{p}<0.001)$. Therefore, the number of illiteracy will be increased could be highly significant impact behind the status of students' dropout.

To help the above idea in interview some respondents described as;

On the other hand, those students whom dropped out from their schooling become burden (load) on their families as well as on the government (KETBs committee participants) 
One of the major reasons for low literacy is the dropout of students at primary level in Pakistan. "A dropout is a pupil who leaves the school for any reason except death before completion of education programs of studies and without transferring to another school" (Kamal. A. 2002) .According to Attaullah, (2000), a dropout is a student, who leaves the school for any reason before the completion of the educational program and without being transferred to any other school. Therefore, dropout of students bring educational wastage in the country could be the impact behind the status of students dropout could be the impact behind the status of students dropout

As can be indicated in item 5 Table 5 showed,84(82.35\%) of the respondents replied strongly agreed and $14(13.72 \%)$ of the respondents replied agreed for the statement Reduce productivity income could be the impact behind the status of students' dropout. Whereas, 2(1.96\%) of the respondents replied strongly disagreed with the statement Reduce productivity income could be the impact behind the status of students' dropout. About $2(1.96 \%)$ of the respondents replied undecided with the statement Reduce productivity income could be the impact behind the status of students' dropout. The score for the total agreed for the item stood at 98(96.07\%) for the statement reduce productivity income could be the impact behind the status of students' dropout. The arithmetic mean score of this item is 4.83 at the standard deviation of 0.424 which is greater than the average mean score 3, showing reduce productivity income could be the impact behind the status of students' dropout in Sewena Woreda, Bale Zone, Oromia. The ANOVA result for this item was (F, 1.737at p<0.001). Therefore, reduce productivity income could be highly significant impact behind the status of students' dropout.

Table 6.Summary Table for ANOVA result for Impacts behind the status of dropout

\begin{tabular}{lcccc}
\hline Source & Sum of Squares & Df & Mean Square & F \\
\hline Between Groups(Combined) & 51.416 & 4 & 12.854 & 24.256 \\
Within Groups & 200.537 & 97 & 2.068 & \\
\hline Total & 251.95 & 101 & & \\
\hline
\end{tabular}

*With $\alpha=0.05$, Fcrit $=1.25$

\section{Discussion of Results}

Looking into the findings of the study it seems that on an individual basis, the reasons for dropping out vary, but generally there are two main categories of factors that lead to dropping out students at primary level. These are out-of-school factors and in-school factors. Out-of-school factors are parent's poverty, parent's lack of motivation and understanding of value education, opportunity cost to the parents by sending the child to school, migration of parents and long distance of schools from homes. While in-school factors include lack of facilities in schools; defective textbooks and curriculum which is beyond the comprehension level of students; and harsh attitude of the teachers with students. Mitigating out-of-school factors that contribute to high dropout rates requires a wide range of policies and actions that focus on poverty reduction through income generation and other methods. However, dealing with in-school factors does not require as much effort (Moe, 1994). Generally, social factors (domestic chores or routine home tasks, home activities, herding, farming etc. early marriage, attitude to girls education, lack of awareness of the benefits of education, lack of parental follow up, and preferring religious education), economic factors ( family income, household chronic poverty and lack of support),school related factors (school environments : shortage of school facilities like; toilets, desk, chair etc. school distance problem and peer influence), student related factors (students low interest towards education, regular absenteeism from school, inappropriate evaluation of students' performance, lack of encouragement given by teachers to students and the number of children in a household),Climatic factors(lack of water, drought and famine) and political factors (migration, boarder conflict and inter-clan conflict) were identified as major and significant factors that contributing for students dropout.

The findings of the study showed that educational wastage in the country, being burden or load on the country in general on the family in the particular, being participated in different criminal activities, the number of illiteracy will be increased and bother the Educational indicators were some of the impacts of students dropout from schools in general study areas in particular. There are two important ways of dealing with or even eliminating in-school factors. The first one is improving the quality of the schools and curricula, and second, training of teachers to use methods that engage children in learning and help them gain high academic achievement. Provisions of facilities such as school places and enrolling pupils are only the aspects of primary education. Unless the children are able to stay through the primary education cycle and acquire with functional effectiveness the basic skills of literacy and numeracy and understanding and reasoning they would not have accomplished the first decisive step in education. This means that dropout and repetition with the associated human and financial wastage need to be minimized and the quality of primary education reflecting the learning gains of the learners enhanced (MoE, 1999). If the government of Ethiopia wants to increase literacy and numeracy rates, it must urgently address the problem of primary school dropouts. 


\section{Recommendations}

From the findings and conclusions of the study, the following recommendations were forwarded.

$\checkmark$ Parents should be aware of the importance and values of education so that they should permit relaxation to their children from domestic chores and home activities, herding, farming etc. during schooling. Early marriage is another social dropout factors that is limiting girls participation in education. to solve this factor in the long run expand and reinforce sex education as well as strict legal reinforcement by taking severe measures on forced early marriages.

$\checkmark$ To eliminate attitudes of girls' education problem; raise the awareness of pastoralists community on the benefits of girls education. All stakeholders should design ways and means to insure the distribution of educational materials to schools; should apply restrict follow up on the purchasing of educational materials with School Grant and Block grant budgets and Woreda and Zonal Education offices should select those parents who cannot able to purchase educational materials should design to help them sustainably. It is also recommended that the Government should provide educational materials, uniforms and monthly fees to poor students so that they may be able to continue their education.

$\checkmark$ It is clear that the pastoralist community have less capacity to support the education system financially and materially because of their poverty. The government has to involve NGOs and create favorable condition under which schools facilities like; toilets, desks, chairs etc

$\checkmark$ The government has to involve different NGOs and create favorable condition under which establishing ABE schools and Facilitators to solve the distance of school for those victims' children. Teachers frequently contact the parents of students and discuss on regular absenteeism of their children with them.

$\checkmark$ Educational stakeholders should strengthen and develop collaborative work between pastoralist community and school community. Moreover teachers should handle their students whenever they perform their regular work and evaluate their students appropriately as well as improve students' encouraging through their activities. Supervisors and educational experts should restrict on monitoring and evaluation of teachers daily activities.

$\checkmark$ The most direct impact of a shortage in rainfall on pastoralists' livelihoods is the drying up of water sources and declining food for livestock. Water and grass are the most important resources for pastoralists. Therefore, Government should involve different NGOs on water sources and rations for pastoralists and other care services in areas of severe shortage to reduce the dropout of students.

$\checkmark$ It was found in the study that migration is one of the major causes of student's dropout. So it is recommended that education stakeholders and concerned governmental bodies should convenient education for the migrated students and the government should decide the exact and specific regional boundaries so as to solve the border conflict that brought community migration and displacement in both Somalia Regional State and Oromia Regional State.

\section{References}

APHA (2018).Chronic Stress and the Risk of High School Dropout. February, 2018

Bale Zone Education Office (2016).Primary School Students Dropout in Bale Zone Pastoralists. Annual Report of 2016/17. Robe.

Bandura, A. (1977). Self-efficacy: toward a unifying theory of behavioural change. Psychological review, 84(2), 191.

Borg, W.R. \& Gall, M. D. (1996).Education Research: An introduction (3rd ed), New York: Longman.

Bouchard,T. (2013).Create the Family Life You Really Want. KelownaParenting.com. Retrieved July 16, 2013, from www.kelownaparenting.com.

Bruneforth, M. (2006).Characteristics of children who drop out of school and comments on the drop-out population compared to the population of out-of school children.Background paper for the EFA Global Monitoring Report 2007.

Creswell, J.W.(2012). Educational research planning, conducting, and evaluating quantitative and qualitative research. (4thed.) London: University of Nebrasca.

Edinyang, S. D., Unimke, S. A., Ubi, I. E., Opoh, F. A., \& Iwok, A. A. (2015). Historical Foundation of Social Studies Education. Calabar: Word of Life Publishers.

Hunt, F. (2008). 'Dropping out from school. 'A cross-country review of literature.' CREATE pathways to access No 16.Consortium for Research on Educational Access, Transitions and Equity: University of Sussex. Retrieved from https://goo.gl/7803LM on 08/02/2017.

Koskei,B.,Tonui,R. and Simiy,C.(2015).School Based Factors as Determinants of Secondary school students; International Journal of Education and Research.vol.3 No.3.

Marie-JoseTheunissen-Lamers, (2016).Stay in or dropout.The pathways to School dropout from a public health perspective. Maastricht 16 November 2016. 
MICS (2014).Serbia Multiple Indicator Cluster Survey and Serbia Roma Settlements Multiple Indicator Cluster Survey, Final Reports. Belgrade: Republički zavod za statistiku \& UNICEF.

MoE (1994).Education and Training Policy and Its Strategy. Addis Ababa: MOE

MoE (2015).Fifth Education Sector Development Programme. Addis Ababa: Government of Ethiopia.

MoE (2017) Education Statistics Annual Abstract (2016/2017). EMIS and ICT Directorate, MOE.

MoE, UNICEF and UNESCO (2016).Global Initiative on Out of School Children - Nepal Country Study, July 2016, UNICEF, Kathmandu, Nepal, 2016.

Morgan, D.L. (2007).Paradigms Lost and Pragmatism Regained: Methodological Implications of Combining Qualitative and Quantitative Methods. Journal of Mixed Methods Research, Volume 1 - Number 1, 48-76.

Mugenda, O. M. \& Mugenda, A.G. (1999).Research Methods, Quantitative and Qualitative approaches, African Centre of Technology Studies, Nairobi: Nairobi.

Nabavi, R. T. (2014).Bandura's Social Learning Theory \& Social Cognitive Learning Theory.http://www.researchgate.net

Omari, I. M. (2011).Concepts and Methods in Educational Research. Dar es Salaam: Oxford University Press

Shahidul, S.M. (2012).Marriage Market and an Effect on Girls' School Dropout in Bangladesh.Journal of Alternative Perspectives in the Social Sciences (4) 2, 552 - 564.

SIDA (2016).Gender perspectives on causes and effects of school dropouts. SE-105 25 Stockholm, Sweden. Office: Valhallavägen 199, Stockholm .January 2016.

Teshome Sirak \&Gamachu Gishe, (2016).Prevalence of Primary School Dropout in Bale Zone Pastoralists of Oromia Region, Southeastern Ethiopia.Department of Psychology, School of Behavioral Science, Madda Walabu University, Bale Robe, Ethiopia. 24 March 2016

UIS and UNICEF (2015).Fixing the Broken Promise of Education for All; Findings from the Global Initiative on Out-of-School Children, UIS, Montreal, Canada, 2015.

UNESCO (2012).Stumbling blocks to universal primary education: Repetition rates decline but dropout rates remain high. Global Education Digest 2012,22.11.2012 issue UNESCO press

UNICEF,(2011). “The EFA Assessment Country Report Pakistan” (2000).USAID, Innovating Pakistan's Education Sector, Available at,http://thinkchangepakistan.wordpress.com/2011/03/05/innovating-pakistans education-sector/on 25/05/2011. Weighted, average, available at: 